\title{
Intercultural Sensitivity and Cross-cultural Adjustment among Malaysian Students Abroad
}

\author{
A.S. Awang-Rozaimie \\ Faculty of Business Management, Universiti Teknologi MARA, Sarawak Malaysia
} Email: awgrozaimi@ sarawak.uitm.edu.my (Corresponding author)

\author{
A.T. Amelia \\ Academy of Language Studies, Universiti Teknologi MARA, Sarawak Malaysia \\ Email: ameliaalfred@sarawak.uitm.edu.my
}

J. Aiza

Academy of Language Studies, Universiti Teknologi MARA, Sarawak Malaysia

Email:aiza@sarawak.uitm.edu.my

\section{S. Siti-Huzaimah}

Academy of Language Studies, Universiti Teknologi MARA, Sarawak Malaysia

Email: huzaimahs@sarawak.uitm.edu.my

\author{
S. Adib \\ Faculty of Computer Science \& Mathematics, Universiti Teknologi MARA, Sarawak Malaysia \\ Email: adib@sarawak.uitm.edu.my
}

\section{Doi:10.5901/jesr.2013.v3n7p693}

\section{Abstract}

\begin{abstract}
Effective socio-cultural integration has formed Malaysia into a nation with harmonious ethnic diversification and living. Cultural understanding is a foundation to sustain a respectful interethnic relationship among multi-ethnic populations in this country. However, Malaysian may experience cross-cultural difficulties when facing a monoculture or unusual cultural environment overseas. Thus, main purpose of the present study is to examine the extent of intercultural sensitivity support the effectiveness of cross-cultural adjustments among Malaysian students while studying and living abroad. Key finding found in the present study shows the magnitude of intercultural sensitivity is moderately facilitate cross-cultural adjustment among Malaysian students abroad. The implications towards the effectiveness of intercultural relations are also highlighted and discussed.
\end{abstract}

Keywords: Intercultural Sensitivity, Cross-cultural Adjustment, Multiethnic Society

\section{Introduction}

Educational industry has contributed significantly to the country's socio-economic development in generating large scale revenues and employment especially in the emerging market. Educational industry players comprise of schools, college, universities, private institutions, vocational educations and special tutoring and other education-related services. The demand for better education and private institution's participation has increased students' mobility and global education competitions. The United Nation's Educational, Scientific and Cultural Organization (UNESCO) Global Monitoring Report 2012 stated in $2007-8$, U.S. constituted $60 \%$ of the global education market. Europe accounted for $15 \%$ of the market and Australia has developed an effective and efficient higher education system. Many countries (such as China, Indonesia, India, Japan, South Korea and Vietnam) offering opportunities for American and Australian extension colleges and universities. Higher education sector considered as a strategic national asset to UK and Australia. The UK government allocated $£ 4.6$ billion a year up to 2015 in science and research which contributing around $£ 59$ billion to the 
UK overall economy. Education created third Australia's largest export industry which generated \$18 billion in 2009. Numbers of Malaysian students abroad rose from 58,963 in 2009 to 79,254 in 2010. 64\% of Malaysian students abroad in 2010 are self-sponsored where Australia marks as the biggest education destination (20,493 students).

International mobility of students' enrolment into a foreign higher academic institution has increased intercultural exposure and contributed to the national socio-economic development through foreign exchange, hospitality and other services. Inability to compromise or make a necessary cultural adaptation creates disappointment, confusion or other psychological discomforts which may affect goal accomplishment of the international assignment. The Global Relocation Survey (GRTS) 2010 reported no previous expatriate experience proven as the main reason for the 7\% of expatriates' prematurely returned back home (off-schedule due to incomplete assignment). Culture has been found to be the main contributing factor to sojourners' failure (GRTS, 2009) where cultural insensitivity leads to financial loss to international sponsorships. The incapability to understand the message and cultural behaviours leads to frustration or annoys those from different cultural backgrounds.

Besides, the reasons for early returns from international assignments are family concerns $(32 \%)$, transfer to a new position within the company ( $21 \%$ ), early completion of the assignment (17\%), cross-cultural adjustment challenges $(8 \%)$, career concerns (4\%), and security concerns (1\%) (GRTS, 2010: p. 48). International mobility has created a multicultural society across the country which requires the highest level of intercultural integration especially in Asia. As shown in Table 1.0, a socio-cultural diversity in the Southeast Asian region has shaped unique cultural systems in the region.

Table 1.0: Ethnic Group Composition in the ASEAN countries

\begin{tabular}{|c|c|c|}
\hline & $\begin{array}{l}\text { Population } \\
\text { (2008 est) }\end{array}$ & $\begin{array}{l}\text { Ethnic Groups } \\
\text { (2000-2006 est.) }\end{array}$ \\
\hline Brunei & 381,371 & Malay $66.3 \%$, Chinese $11.2 \%$, Indigenous $3.4 \%$, Other $19.1 \%$ \\
\hline Cambodia & $13,388,910$ & Khmer $90 \%$, Vietnamese $5 \%$, Chinese $1 \%$, other $4 \%$ \\
\hline Indonesia & $237,512,352$ & $\begin{array}{l}\text { Javanese } 40.6 \% \text {, Sundanese } 15 \% \text {, Madurese } 3.3 \% \text {, Minangkabau } 2.7 \% \text {, Betawi } 2.4 \% \text {, } \\
\text { Bugis } 2.4 \% \text {, Banten } 2 \% \text {, Banjar } 1.7 \% \text {, other or unspecified } 29.9 \% \text { ( } 2000 \text { census) }\end{array}$ \\
\hline Lao PDR & $6,677,534$ & Lao $55 \%$, Khmou $11 \%$, Hmong $8 \%$, other (over 100 minor ethnic groups) $26 \%$ \\
\hline Malaysia & $25,274,132$ & Malay $50.4 \%$, Chinese $23.7 \%$, Indigenous $11 \%$, Indian $7.1 \%$, others $7.8 \%$ \\
\hline Myanmar & $\begin{array}{l}56,002.6 \\
\text { thousands }\end{array}$ & $\begin{array}{l}\text { Burman } 68 \% \text {, Shan } 9 \% \text {, Karen } 7 \% \text {, Rakhine } 4 \% \text {, Chinese } 3 \% \text {, Indian } 2 \% \text {, Mon } 2 \% \text {, other } \\
5 \%\end{array}$ \\
\hline Philippines & $\begin{array}{l}88,700 \\
\text { thousands }\end{array}$ & $\begin{array}{l}\text { Tagalog } 28.1 \% \text {, Cebuano } 13.1 \% \text {, llocano } 9 \% \text {, Bisaya/ Binisaya } 7.6 \% \text {, Hiligaynon Ilonggo } \\
7.5 \% \text {, Bikol } 6 \% \text {, Waray } 3.4 \% \text {, other } 25.3 \%\end{array}$ \\
\hline Singapore & $4,608,167$ & Chinese $76.5 \%$, Malay $13.8 \%$, Indian $8.1 \%$, other $1.6 \%$ \\
\hline Thailand & $\begin{array}{l}64,763.0 \\
\text { thousands }\end{array}$ & Thai $75 \%$, Chinese $14 \%$, other $11 \%$ \\
\hline Viet Nam & $86,116,560$ & $\begin{array}{l}\text { Viet } 80 \% \text {, Khmer } 10 \% \text {, Tay } 1.9 \% \text {, Thai } 1.74 \% \text {, Muong } 1.49 \% \text {, Hoa } 1.13 \% \text {, Nun } 1.12 \% \text {, } \\
\text { Hmong } 1.03 \%\end{array}$ \\
\hline
\end{tabular}

Source: CIA, the World Factbook

Above all, cultural integration demands a high tolerance, compromising and understanding to create a harmonic multicultural society. The United Nations Educational, Scientific and Cultural Organization (UNESCO) world report on the Cultural Diversity and Intercultural Dialogues indicated that, managing cultural diversity is a crucial issue which potentially can be the source of cultural disputes, separation and conflicts. For example, ethnic conflict such as "attacks on Chinese (property, and the rape and murder of Chinese women) in Jakarta in May 1998 and clashes between local people and Madurese immigrants in West and Central Kalimantan 1997 - 2001" to name a few (Colombijn 2002). Thus, intercultural understanding, awareness and sensitivity are essential to understand the complexity of society and social concern. Hence, the present study was conducted to answer the research question: to what extent Malaysian students adjust in different cultural settings abroad? Comparatively with expatriation studies that have been conducted, there were limited numbers of studies that involved Malaysian students abroad. Specifically, the present study also aims to explore the prediction on facilitation of intercultural sensitivity toward cross-cultural adjustment among Malaysian students abroad. 


\section{Literature Review}

Culture is a fundamental element which contributes to the effectiveness of intercultural relationships and other human interactions across-borders. Cultural frame of references (values, beliefs, norms and attitudes) is shaped through a learning process which explains the way of how people behave in certain ways (Torbiorn 1985). A behavioural learning process involves "... a retention or remembrance of observed behaviour, reproduction or acting, as like the observed behaviour and motivational outcomes or a positive reason for adapting behaviour" (Bandura, 1977: p.193). Besides, Hofstede (1983) defined culture as a "collective mental programming or a system of collective held values, shared with other members and is used to distinguish the members from other group" (p. 76). Developing intercultural effectiveness challenges a person's psychological and physical ability to understand different ways of being cultured.

Bandura's Social Learning Theory underlines an explanation on a symbolic environment which plays significant roles in influencing people's ways of life and intercultural interaction. Intercultural relations effectiveness depends on the sensitivity and integration of social system to create harmonious socio relationships. In social integration, a mutual connection is created through right cultural imitation and modelling processes. However, misleading imitation of the learning process may create inappropriate behaviour such as unpleasant, unnecessary, unwelcome, threaten, forces, annoying and show one's intercultural incompetency (Selmer, 2004). In addition, lack of cultural sensitivity and interest to other cultures typically lead to anxiety and uncertainty in intercultural encounters (Gudykunst \& Nishida, 2001). An extrovert person and those who possesses enough intercultural sensitivity show a comfort in the other's way of life, have wide cultural perspectives and are knowledgeable about the different cultural frame of references.

Well-adjusted sojourners in a different cultural environment contribute to the assignments' goal accomplishment. At the same time, excitement and learning culture abroad enhance their life experience. On the other hands, maladjustment creates mobility difficulties while sojourning overseas due to the unavailability familiar materials and life support and misunderstanding of the host nationals' way of life culturally. Cultural shock literatures (example sees, Adler, 1975; Brein \& David, 1971; Oberg, 1960; Ward, Bochner \& Furnham, 2001) deliberated that the difficulties interacting with host nationals caused the misinterpretation of cultural clues which seem unreasonable, annoying or impolite either from sojourners or host national point of views.

In addition, intercultural interaction and mobility across the cultural environment gives various psychological and sociocultural implications on sojourners when sojourning abroad (Searle \& Ward, 1990). The psychological effect is a rational or cognitive comparison between what is perceived as right or wrong which shaped mental well-being (Searle \& Ward, 1990). Sociocultural adjustment shows the extend sojourners being able to live or interact with cultural surroundings (Searle \& Ward, 1990). This disillusionment caused by sojourners' knowledge about ways of life (cultural mindset) is different with their experience abroad (Torbiorn, 1985; Ward et al., 2001). Unfamiliarity on foreign culture cues (value, attitudes and belief) has found limit harmonic interaction with locals by East Asian students sojourn in New Zealand (Lewthwaite, 1996). Moreover, a massive cultural difficulty has reported by western sojourners in Asian multiethnic society especially in China (GRTS, 2009).

Scholars (examples, Rasmussen, Lloyd \& Wielandt, 2005; Shaftel, Shaftel \& Ahluwalia, 2007) emphasized sufficient cultural exposure, knowledge, information and experiences facilitating cross-cultural adjustment. In addition, Rasmussen et. al. (2005) demonstrated that a high level of cultural sensitivity has significant impact towards a person's beliefs, attitudes, behaviours and, lifestyles and occupation. Besides, William (2005) has shown students who studied abroad had the strongest intercultural communication competency compared to local students. In particular, intercultural sensitivity refers to the ability of a person to understand the culture (beliefs, norms \& attitude) and cultural behaviour (Chen \& Starosta, 1996). Intercultural sensitivity is an affective response on feeling and emotions toward cultural similarity and differences (Chen \& Starosta, 2000) from his/her own and others' perspectives. Hence, having sufficient cultural sensitivity is vital to avoid cultural surprises or disorder such as racism, stereotyping, ethnocentrism (Graf, 2004; Stahl, 2000), stereotyping (Clausen, 2010) or social desirability (Ones \& Viswesvaran, 1999).

Furthermore, having adequate cultural knowledge and skills stimulates intercultural competency (Matveev \& Milter, 2004). For example, mianzi (face-saving) and guanxi (relationship) are key concepts in Chinese culture to ensure the effectiveness of business connection in China (see Buckley, Clegg \& Tan, 2006; Chen, 2006; Friedman, Dyke \& Murphy, 2009). Appropriate intercultural communication sensitivity and multiculturalism reduce ethnocentrism sentiment in a multicultural environment (Dong, Day \& Collaço, 2008). Yu and Chen (2008) found intercultural sensitivity has a significant and positive relationship with conflict management style. Hence, sensitivity to cultural differences develop intercultural competency (Chen \& Starosta, 2000) and perceive to facilitate sojourners' cross-cultural adjustment internationally. Moreover, Chen and Starosta (2000) posited 5 dimensions of intercultural sensitivity include: interaction 
engagement, respect for cultural differences, interaction confidence, interaction enjoyment and interaction attentiveness. Therefore, the magnitude of sojourners' intercultural sensitivity towards the effectiveness of cross-cultural adjustment among Malaysian students abroad hypothesized as:

- Hypothesis 1a: Interaction Engagement is positively associated with psychological adjustment among Malaysian students abroad.

- Hypothesis 1b: Interaction Engagement is positively associated with sociocultural adjustment among Malaysian students abroad.

- Hypothesis 2a: Respect for Cultural Differences is positively associated with psychological adjustment among Malaysian students abroad.

- Hypothesis 2b: Respect for Cultural Differences is positively associated with sociocultural adjustment among Malaysian students abroad.

- Hypothesis 3a: Interaction Confidence is positively associated with psychological adjustment among Malaysian students abroad.

- Hypothesis 3b: Interaction Confidence is positively associated with sociocultural adjustment among Malaysian students abroad.

- Hypothesis 4a: Interaction Enjoyment is positively associated with psychological adjustment among Malaysian students abroad.

- Hypothesis 4b: Interaction Enjoyment is positively associated with sociocultural adjustment among Malaysian students abroad.

- Hypothesis 5a: Interaction Attentiveness is positively associated with psychological adjustment among Malaysian students abroad.

- Hypothesis 5b: Interaction Attentiveness is positively associated with sociocultural adjustment among Malaysian students abroad.

Mutual understanding of cultural elements, compromises and substantial cultural knowledge about appropriate behaviour will facilitate sojourners' effectiveness in working and living abroad. Sufficient visible (behaviour and material possession) and intrinsic (perception, attitude, value and belief) cultural knowledge is an essential for intercultural communication and effectiveness (Bhaskar-Shrinivas, Harrison, Shaffer \& Luk, 2005; Bjerregaard, Lauring \& Klitmoller, 2009; Mendenhall, Stevens, Birds \& Oddou, 2008) and help sojourners to avoid any possibilities of cultural misconduct. These scenarios lead to the proposition of this research as intercultural interaction gives cognitive impact on sojourners' psychological well-being and sociocultural adjustment abroad. Delineated from the studies as mentioned above, an intercultural sensitivity rationalizes in the present study is perceived as affective responses to the recognition and understanding on cultural skills, knowledge and the way of life of different cultural group. Thus, major aim of the present study is to establish a more feasible prediction of intercultural sensitivity towards cross-cultural adjustment among Malaysian students abroad.

\section{Research Methodology}

Sojourners' intercultural sensitivity posited in the present study as an ability to establish appropriate affective intercultural responses which predicts the effectiveness of cross-cultural adjustment among Malaysian students abroad. Thus, intercultural sensitivity was measured using the Intercultural Sensitivity Scale (ISS) as developed by Chen and Starosta (2000). The ISS is measured using 5-level of Likert scale, ranging from 1 (strongly disagree) to 5 (strongly agree) with 24 manifested items. A predictive validity of ISS accounted Cronbach's a between 0.85 and 0.88 (Chen \& Starosta, 2000). An example of the indicator is, "I enjoy interacting with people from different cultures". Acceptable validity of ISS over its five dimensions was proves by studies (sees, Fritz, Mollenberg \& Chen, 2002; Peng, 2006; Yu \& Chen, 2008) tested in various cultural group namely American, German and Chinese.

The Mental Health Inventory (MHI-5) (Berwick, Murphy, Goldman, Ware, Barsky \& Weinstein, 1991) was adopted in the present study to measure Malaysian students' psychological adjustment. MHI-5 manifested by five indicators (items), containing the elements of behavioural dysfunction (anxiety), feeling of psychological distress (depression and behavioural / emotional control) and generally positive effect. An example of the indicator is, "How much of the time during the past month have you been a nervous person?" The measure of the scale is based on the 6-level Likert scales, ranging from 1 (none of the time) to 6 (all of the time). Higher scores on MHI-5 indicate a person was psychologically adjusted which indicated their ability to encounter cultural stress effectively.

The status of Malaysian students' abilities in adjusting their life with sociocultural environments was measured by 
using the Sociocultural Adaptation Scale (SCAS) (Ward \& Kennedy, 1999). SCAS has validated using various sojourners samples especially Malaysian and Singaporean respondents; and internal consistency index of the measures ranged from 0.75 to 0.91 ( $M=0.85$ ) was found. The 29-items SCAS measured with five levels of Likert scales ranging from 1 (no difficulty) to 5 (extreme difficulty). The respondents may indicate the difficulty level of their past experience dealing with living events in the host country (see, Ward \& Kennedy, 1999). An example of the indicator is, "How much difficulty you have experienced during the past month with the activities (such as making friends)". Holistic reviews on the use of the scale have found the Cronbach's alpha reliability of SCAS had reported a range of 0.81 to 0.87 across 16 cross-sectional and four longitudinal studies. Notably, the studies emphasized culture-specific skills, behavioural dimensions of adaptation to change, and the significance of intercultural interactions (Ward \& Kennedy, 1999).

Later, a purposive sampling has been used to identify Malaysian students abroad through an online survey. A respondents' recruitment screening only incorporates those studying and living abroad which identified through the Malaysian Students Department (MSD), Malaysian embassy abroad. The students' respondents include those studying the bachelor degree, master's degree and doctorate degree. In the present study, the Malaysian student population abroad is estimated by 79,254 (2010). Thus, a general rule was used to determine the sample size whereas the minimum number of respondents needed has to be at least five times of the number of variables to be analyzed. An acceptable sample size would be a ten to one ratio. It was proposed that a minimum of 20 cases for each variable is conducted (Hair, Black, Babin, Anderson \& Tatham, 2006). In the present study, there are 3 constructs that build the research framework ( 1 independent variable, 2 dependent variables) and in total, there are 7 dimensions ( 5 independent variables, 2 dependent variables) incorporated. Hence, a total minimum of 140 samples (7 dimensions x 20 cases) were sufficient and it showed satisfactory number of the sample size.

\section{Findings}

From 500 Malaysian students contacted by email, 248 responded which yield $49.6 \%$ response rate. However, only 187 responses are usable for further data analyses. Detailed respondents' demographic was shown in Table 2.0 and Table 3.0. Majority of respondents aged between 31 to $35(22.5 \%)$, Female $(61.5 \%)$, single (67.9\%), Muslim (56.1\%), studying a doctorate degree (35.8\%), being sponsored (45.5\%) and with past overseas experiences $(28.9 \%)$ (although $65.2 \%$ of respondents were unspecified whether they are with or without past overseas experiences). The respondents claimed that they are studying and living in 25 different countries around the globe and the majority $(25.13 \%)$ are in Australia.

Table 2.0. Respondents' Profile

\begin{tabular}{|c|c|c|c|c|c|}
\hline & Frequency & Percent & & Frequency & Percent \\
\hline Age & & & Gender & & \\
\hline$\overline{<25}$ & 38 & 20.3 & Male & 72 & 38.5 \\
\hline $26-30$ & 28 & 15.0 & Female & 115 & 61.5 \\
\hline $31-35$ & 42 & 22.5 & Total & 187 & 100.0 \\
\hline $36-40$ & 28 & 15.0 & & & \\
\hline $41-45$ & 29 & 15.5 & Studying Level & & \\
\hline $46-50$ & 22 & 11.8 & $\overline{\text { Bachelor Degree }}$ & 42 & 22.5 \\
\hline \multirow[t]{2}{*}{ Total } & 187 & 100.0 & Masters Degree & 64 & 34.2 \\
\hline & & & Doctoral Degree & 67 & 35.8 \\
\hline Marital Status & & & Others & 14 & 7.5 \\
\hline Single & 127 & 67.9 & Total & 187 & 100.0 \\
\hline Living with the Other & 3 & 1.6 & & & \\
\hline Married & 52 & 27.8 & $\underline{\text { Studying Mode }}$ & & \\
\hline Separated & 1 & .5 & Self-Initiated & 72 & 38.5 \\
\hline Divorced & 2 & 1.1 & Sponsorship & 85 & 45.5 \\
\hline Widowed & 2 & 1.1 & Unspecified & 30 & 16.0 \\
\hline Total & 187 & 100.0 & Total & 187 & 100.0 \\
\hline Religious Belief & & & Past Experiences & & \\
\hline Islam & 105 & 56.1 & $\overline{\text { With Experiences }}$ & 54 & 28.9 \\
\hline Christian & 37 & 19.8 & Non-Experienced & 11 & 5.9 \\
\hline Buddha & 17 & 9.1 & Unspecified & 122 & 65.2 \\
\hline Hindu & 15 & 8.0 & Total & 187 & 100.0 \\
\hline Others & 13 & 7.0 & & & \\
\hline Total & 187 & 100.0 & & & \\
\hline
\end{tabular}


Table 3.0. Location of Malaysian students overseas

\begin{tabular}{|c|c|c|c|c|c|}
\hline Location & Frequency & Location & Frequency & Location & Frequency \\
\hline Australia & 27 & Japan & 1 & Singapore & 28 \\
\hline Brunei Darussalam & 4 & Jordan & 4 & South Africa & 2 \\
\hline China & 2 & Mexico & 2 & Sweden & 1 \\
\hline Egypt & 14 & Netherland & 2 & Thailand & 6 \\
\hline France & 5 & New Zealand & 21 & Turkey & 5 \\
\hline Germany & 3 & Philippines & 1 & UK & 5 \\
\hline India & 2 & Portugal & 1 & USA & 15 \\
\hline Indonesia & 10 & Russia & 2 & Unspecified & 17 \\
\hline Italy & 3 & Saudi Arabia & 4 & Total & 187 \\
\hline
\end{tabular}

*Note: $\mathrm{N}=25$ Location Overseas, arranges alphabetically.

For instance, a regression assumption test has shown that the data on the dependent variable (psychological and sociocultural adjustment) are skewed with Z-score of -1.904 and -4.753 respectively. Besides, Kolmogorov-Smirnov test of normality rejected the normality hypothesis of the data with significant level greater than 0.5 (Hair et. al, 2011). Hence, the nonparametric analyzing using the Partial Least Square (PLS) (Henseler, Ringle \& Sinkovics, 2009) provides robustness statistical prediction techniques which optimized the proportion of variance of the dependent construct that is explained by the predictive constructs. The measurement and structural model of the present study was analyzed using the SmartPLS software version $2.0 \mathrm{M} 3$ with temporary license to use obtained from the developer's website. The relationship predictions between intercultural sensitivity and cross-cultural adjustment among Malaysian students overseas analyze through measurement and structural model are discussed in the following section.

\subsection{Measurement Model}

Initial sets of established reliability (Cronbach alpha, composite reliability and average variance explained) were shown as in Table 4.0. As compared to Cronbach's a, composite reliability (CR) shows better internal consistency indicators of the variable as a construct. The findings show although some of the constructs (cultural, interaction and self awareness) accounted low Cronbach's a, the Average Variance Explained (AVE) and CR has sufficient reliability scores after receiving some 'loading treatment'. An outer loading of the indicators was diagnosed and has identified 29 manifested indicators with the lowest loading being deleted from the list. Deleted items include: 2 psychological adjustment items; 19 sociocultural adjustment items; 3 interaction engagement items, 2 respect for cultural differences items; 2 interaction confidence items; and 1 interaction attentiveness item. Deleted items indicated lowest regression of the measured items from the respondents' perspectives.

Table 4.0: Measurement Model (reliability and validity)

\begin{tabular}{llllllll}
\hline Model Construct & Measurement & Loadings & $\alpha$ & CR & AVE & $\begin{array}{l}\text { Standardized } \\
\text { estimate }\end{array}$ & $t$-value \\
\hline Psychological & MHI5b & 0.794 & $\mathbf{0 . 6 8 7}$ & 0.824 & 0.614 & 0.216 & 1.535 \\
Adjustment (PSY) & MHI5c & 0.622 & & & & 0.230 & 1.363 \\
& MHI5d & 0.908 & & & & 0.153 & $3.892^{* * *}$ \\
\hline Sociocultural & SCAS05 & 0.771 & 0.897 & 0.915 & 0.519 & 0.046 & $4.198^{* * *}$ \\
Adjustment (SOC) & SCAS08 & 0.784 & & & & 0.051 & $2.684^{* * *}$ \\
& SCAS09 & 0.695 & & & & 0.039 & $3.068^{* * *}$ \\
& SCAS10 & 0.741 & & & & 0.050 & $3.332^{* * *}$ \\
& SCAS17 & 0.722 & & & & 0.051 & $2.242^{* *}$ \\
& SCAS18 & 0.762 & & & & 0.043 & $4.378^{* * *}$ \\
& SCAS21 & 0.652 & & & & 0.049 & $1.924^{*}$ \\
& SCAS26 & 0.750 & & & & 0.038 & $3.397^{* * *}$ \\
& SCAS28 & 0.605 & & & & 0.054 & $2.267^{* *}$ \\
& SCAS29 & 0.705 & & & 0.518 & 0.230 & 1.412 \\
\hline Interaction & ISS01 & 0.627 & $\mathbf{0 . 6 8 8}$ & 0.809 & 0.512 & 0.182 & $2.414^{* *}$ \\
Engagement & ISS13 & 0.826 & & & & 0.213 & 1.263 \\
(011ntEng) & ISS21 & 0.669 & & & & & \\
& & & & & & &
\end{tabular}




\begin{tabular}{|c|c|c|c|c|c|c|c|}
\hline & ISS23 & 0.741 & & & & 0.168 & $2.023^{* *}$ \\
\hline \multirow{4}{*}{$\begin{array}{l}\text { Respect for Cultural } \\
\text { Differences } \\
\text { (02RspCultDiff) }\end{array}$} & ISS02 & 0.776 & 0.679 & 0.802 & 0.504 & 0.243 & 1.607 \\
\hline & ISS07 & 0.721 & & & & 0.207 & 1.139 \\
\hline & ISS08 & 0.720 & & & & 0.261 & $1.760^{*}$ \\
\hline & ISS20 & 0.612 & & & & 0.282 & 1.134 \\
\hline \multirow{3}{*}{$\begin{array}{l}\text { Interaction Confidence } \\
\text { (03IntConf) }\end{array}$} & ISS10 & 0.756 & 0.576 & 0.777 & 0.538 & 0.237 & $2.179^{* *}$ \\
\hline & ISS05 & 0.785 & & & & 0.234 & 1.457 \\
\hline & ISSO6 & 0.652 & & & & 0.286 & $1.724^{*}$ \\
\hline \multirow{3}{*}{$\begin{array}{l}\text { Interaction Enjoyment } \\
\text { (04IntEnjy) }\end{array}$} & ISS09 & 0.783 & 0.803 & 0.879 & 0.709 & 0.178 & 1.495 \\
\hline & ISS12 & 0.867 & & & & 0.130 & $3.087^{\star * *}$ \\
\hline & ISS15 & 0.872 & & & & 0.191 & $2.650^{* * *}$ \\
\hline \multirow{2}{*}{$\begin{array}{l}\text { Interaction } \\
\text { Attentiveness } \\
\text { (05IntAttn) }\end{array}$} & ISS14 & 0.372 & 0.527 & 0.213 & 0.519 & 0.518 & 0.230 \\
\hline & ISS17 & 0.994 & & & & 0.450 & $2.332^{\star *}$ \\
\hline
\end{tabular}

*note: $t-v a l u e ~>1.645^{*}(p<0.1)$; t-value $>1.960^{* *}(p<0.05) ;$ t-value $>2.576^{* * *}(p<0.01)$

Additionally, the data have shown an acceptable convergent validity, checked through cross-loading procedures (see Table 5.0). A Fornell-Larcker criterion also has been performed to examine the discriminant validity of the constructs. A correlation matrix of the latent constructs' and their VAVE scores (bold in the diagonal) provide a verification to support discriminant validity assumption as shown in the Table 6.0. Hence, with an acceptable range of reliability and validity of the measurement model, the structural model examination was preceded.

Table 5.0. Convergent Validity (Cross-loading)

\begin{tabular}{lccccccc}
\hline & $P S Y$ & SOC & 01IntEng & 02RspCultDiff & 03IntConf & 04IntEnjy & 05IntAttn \\
\hline MHI5b & $\mathbf{0 . 7 9 4}$ & 0.018 & -0.026 & 0.110 & -0.008 & 0.046 & -0.088 \\
MHI5c & $\mathbf{0 . 6 2 2}$ & -0.047 & 0.044 & 0.101 & 0.041 & -0.076 & 0.020 \\
MHI5d & $\mathbf{0 . 9 0 8}$ & -0.068 & -0.038 & 0.102 & 0.079 & -0.061 & -0.131 \\
SCAS05 & 0.004 & $\mathbf{0 . 7 7 1}$ & -0.158 & -0.082 & -0.120 & -0.161 & 0.091 \\
SCAS08 & -0.004 & $\mathbf{0 . 7 8 4}$ & -0.165 & -0.133 & -0.213 & -0.098 & -0.008 \\
SCAS09 & -0.055 & $\mathbf{0 . 6 9 5}$ & -0.113 & -0.077 & -0.071 & -0.103 & 0.050 \\
SCAS10 & -0.001 & $\mathbf{0 . 7 4 1}$ & -0.109 & -0.041 & -0.098 & -0.109 & 0.120 \\
SCAS17 & -0.021 & $\mathbf{0 . 7 2 2}$ & -0.004 & -0.001 & -0.038 & -0.125 & 0.106 \\
SCAS18 & -0.041 & $\mathbf{0 . 7 6 2}$ & -0.182 & -0.055 & -0.172 & -0.179 & 0.036 \\
SCAS21 & -0.011 & $\mathbf{0 . 6 5 2}$ & -0.029 & -0.038 & -0.075 & -0.077 & 0.073 \\
SCAS26 & -0.079 & $\mathbf{0 . 7 5 0}$ & -0.092 & -0.034 & -0.161 & -0.089 & 0.046 \\
SCAS28 & -0.155 & $\mathbf{0 . 6 0 5}$ & -0.106 & -0.082 & -0.132 & -0.143 & 0.007 \\
SCAS29 & -0.026 & $\mathbf{0 . 7 0 5}$ & -0.136 & -0.058 & -0.101 & -0.095 & 0.015 \\
ISS01 & -0.024 & -0.107 & $\mathbf{0 . 6 2 7}$ & 0.368 & 0.286 & 0.298 & 0.330 \\
ISS13 & 0.007 & -0.149 & $\mathbf{0 . 8 2 6}$ & 0.373 & 0.405 & 0.429 & 0.349 \\
ISS21 & -0.013 & -0.089 & $\mathbf{0 . 6 6 9}$ & 0.329 & 0.359 & 0.449 & 0.335 \\
ISS23 & -0.027 & -0.111 & $\mathbf{0 . 7 4 1}$ & 0.451 & 0.338 & 0.343 & 0.362 \\
ISS02 & 0.098 & -0.062 & 0.290 & 0.776 & 0.222 & 0.508 & 0.302 \\
ISS07 & 0.051 & -0.049 & 0.427 & $\mathbf{0 . 7 2 1}$ & 0.266 & 0.518 & 0.317 \\
ISS08 & 0.113 & -0.075 & 0.538 & $\mathbf{0 . 7 2 0}$ & 0.290 & 0.240 & 0.378 \\
ISS20 & 0.082 & -0.047 & 0.202 & $\mathbf{0 . 6 1 2}$ & 0.117 & 0.258 & 0.087 \\
ISS05 & 0.042 & -0.141 & 0.271 & 0.162 & $\mathbf{0 . 7 8 5}$ & 0.259 & 0.260 \\
ISS06 & 0.012 & -0.099 & 0.378 & 0.209 & $\mathbf{0 . 6 5 2}$ & 0.376 & 0.189 \\
ISS10 & 0.064 & -0.127 & 0.435 & 0.336 & $\mathbf{0 . 7 5 6}$ & 0.382 & 0.205 \\
ISS09 & 0.020 & -0.104 & 0.421 & 0.521 & 0.387 & $\mathbf{0 . 7 8 3}$ & 0.252 \\
ISS12 & -0.027 & -0.142 & 0.520 & 0.441 & 0.370 & $\mathbf{0 . 8 6 7}$ & 0.404 \\
ISS15 & -0.078 & -0.167 & 0.398 & 0.389 & 0.389 & $\mathbf{0 . 8 7 2}$ & 0.374 \\
ISS14 & -0.023 & -0.053 & 0.515 & 0.207 & 0.229 & 0.228 & $\mathbf{0}$ \\
ISS17 & -0.099 & 0.067 & 0.510 & 0.399 & 0.312 & 0.425 & $\mathbf{0 . 9 9 4}$ \\
\hline & & & & & & \\
\hline
\end{tabular}


Table 6.0. Divergent Validity (Fornell-Larcker criterion)

\begin{tabular}{|c|c|c|c|c|c|c|c|}
\hline Dimensions & 01/ntEng & 02RspCultDiff & 03IntConf & 04IntEnjy & 05IntAttn & PSY & SOC \\
\hline 011ntEng & 0.720 & & & & & & \\
\hline 02RspCultDiff & 0.526 & 0.710 & & & & & \\
\hline 03IntConf & 0.483 & 0.320 & 0.733 & & & & \\
\hline 04IntEnjy & 0.523 & 0.514 & 0.450 & 0.842 & & & \\
\hline 05IntAttn & 0.475 & 0.394 & 0.300 & 0.419 & 0.751 & & \\
\hline PSY & -0.018 & 0.129 & 0.057 & -0.045 & -0.101 & 0.784 & \\
\hline SOC & -0.162 & -0.085 & -0.169 & -0.170 & 0.077 & -0.050 & 0.721 \\
\hline
\end{tabular}

\subsection{Structural Model}

Shown in Table 7.0, only 2 latent dependent variables showed statistically significant predicts sociocultural adjustment among Malaysian students abroad. First, respect for cultural differences was found to have high statistical significance predict psychological adjustment (02RspCultDiff PSY: $\beta=0.112, t_{0.05}=2.242$ ) among Malaysian students while living and studying abroad. Thus, sufficient empirical evidence to support Hypothesis 2a that is "Respect for Cultural Differences is positively associated with psychological adjustment among Malaysian students abroad". Second, interaction enjoyment is also found to have statistical significance predicts sociocultural adjustment among Malaysian students' (04IntEnjy SOC: $\beta=0.090, t_{0.10}=1.646$ ) while living and studying abroad. Thus, sufficient empirical evidence to support Hypothesis $2 \mathrm{~b}$ that is "Interaction Enjoyment is positively associated with sociocultural adjustment among Malaysian students abroad". However, the structural coefficient also suggested interaction engagement (01IntEng PSY: $\beta=0.135)$ appeared as the best predictor of psychological adjustment, followed by interaction attentiveness (05IntrAttn PSY: $\beta=0.133$ ), interaction enjoyment (04IntEnjy PSY: $\beta=0.121$ ), interaction confidence (03IntConf PSY: $\beta$ $=0.116$ ) and respect for cultural differences (02RspCultDiff PSY: $\beta=0.112)$. On the other hand, the structural coefficient suggests interaction attentiveness (05IntAttn SOC: $\beta=0.178$ ) best predictor of sociocultural adjustment, followed by interaction engagement (01IntEng SOC: $\beta=0.112$ ), interaction confidence (03IntConf SOC: $\beta=0.099$ ), respect for cultural differences (02RspCultDiff SOC: $\beta=0.095$ ) and interaction enjoyment (04IntEnjy SOC: $\beta=0.090$ ).

Overall, the latent dependent variables (interaction engagement, respect for cultural differences, interaction confidence, interaction enjoyment and interaction attentiveness) have explained $6 \%$ of variance $\left(R^{2}\right)$ on the latent independent variables (psychological adjustment). On the other hand, the latent dependent variables (interaction engagement, respect for cultural differences, interaction confidence, interaction enjoyment and interaction attentiveness) have explained $9 \%$ of variance $\left(R^{2}\right)$ on the latent independent variables (sociocultural adjustment). The implication of the result will be discussed in the following section.

Table 7.0: Structural Model (relationship prediction)

\begin{tabular}{lccl}
\hline \multicolumn{1}{c}{ Relationship } & Coefficient & $t$-value & \multicolumn{1}{c}{ Significant } \\
\hline 01IntEng PSY & 0.135 & 0.493 & Not significant \\
01IntEng SOC & 0.112 & 1.377 & Not significant \\
02RspCultDiff PSY & 0.112 & $\mathbf{2 . 2 4 2}$ & Significant \\
02RspCultDiff SOC & 0.095 & 0.112 & Not significant \\
03IntConf PSY & 0.116 & 0.956 & Not significant \\
03IntConf SOC & 0.099 & 1.039 & Not significant \\
04IntEnjy PSY & 0.121 & 1.048 & Not significant \\
04IntEnjy SOC & 0.090 & $1.646^{*}$ & Significant \\
05IntAttn PSY & 0.133 & 1.117 & Not significant \\
05IntAttn SOC & 0.178 & 1.342 & Not significant
\end{tabular}

*note: t-value $>1.645^{\star}(p<0.1)$; t-value $>1.960^{* *}(p<0.05)$; t-value $>2.576^{* * *}(p<0.01), 500$ samples bootstrapping

\section{Discussions}

The aim of the present study is to predict facilitation of intercultural sensitivity towards Malaysian students' cross-cultural adjustment abroad. The results have shown that only one intercultural sensitivity dimension (respect for cultural differences) was found positively predict psychological adjustment among Malaysian students abroad. Additionally, 
intercultural sensitivity dimension of interaction enjoyment are clearly appeared as the only intercultural sensitivity dimension that positively predict sociocultural adjustment among Malaysian students abroad. The result found in the present study indicates Malaysian students' shows high value of respect on the cultural differences. Besides, there are enjoying to the different cultural environment while studying and living abroad. The multiracial society of Malaysia proves had established some magnitude of intercultural respect and sensitivity among Malaysian students. Unfortunately, insignificant result provides weak statistical support to predict intercultural sensitivity dimensions towards cross-cultural adjustment among Malaysian students abroad. However, the insignificant result indicates the students are adjusted to the different cultural setting and probably have not felt direct effect of the intercultural sensitivity dimensions on their cross-cultural adjustment.

The present study gives support to the studies (see, Rasmussen et. al., 2005; Shaftel, Shaftel \& Ahluwalia, 2007) where cultural exposure, knowledge, information and experiences build sufficient affective responses among Malaysian students when encounter cultural differences abroad. The results also show that Malaysian students have certain magnitude of intercultural competency (Matveev \& Milter, 2004) that facilitates their cross-cultural adjustment internationally. This finding sustain studies by William (2005), and Chen and Starosta $(1996,2000)$ where intercultural sensitivity determine the ability of a person to identify the similarity and differences of cultural context and contact. An affective cultural ability helps a person to avoid cross-cultural difficulties and intercultural conflict as argued by scholars (Clausen, 2010; Dong et. al, 2008; Graf, 2004; Ones \& Viswesvaran, 1999; Stahl, 2000; Yu and Chen, 2008). Furthermore, sensitive to cultural differences may lead an individual transformation from ethnocentrism into ethnos relativism (cultural competent) status (Bhawuk \& Brislin, 1992; Greenholtz, 2000). Cultural knowledge is essential to create mutual benefits of intercultural relationship. Thus, acquiring enough culture knowledge and acknowledging individual cultural differences, the role of family, gender, age and seniority, religion, customs and belief in intercultural relationship are important especially in regards to the Asian culture. As mentioned by Hall (1959), high contacts of Asian culture incorporated personal values in interpersonal interactions and relations. Therefore, it is important to gain enough cultural knowledge to avoid being racist or ethnocentric in intercultural relationships.

Nevertheless, the finding of the present study provides further reliability and validity of the ISS in measuring intercultural sensitivity as postulated by Chen and Starosta (1996). Besides, showing respect especially towards the other from different personal and cultural background is vital to create a mutual interpersonal relationship. Thus, by having enough cultural knowledge and sensitivity of such differences could help to avoid imposing self-judgement, being racist and ethnocentric in intercultural relations. This quality is important to gain respect and trust when dealing with different cultural expectation, consideration and establishes good manners.

However, there are a few limitations of the present study which may offer opportunities for future studies to establish better prediction and measures of intercultural sensitivity and cross-cultural adjustment. First, the statistical insignificant result might shows the applicability of ISS in measures cross-cultural adjustment requires further psychometric investigation. The deletion procedures and low reliability scores as found in the present study indicate the need for further psychometric treatments. There are possibilities of social desirability problems that affect small effect on the intercultural sensitivity measures in cross-cultural adjustment prediction. Thus, future study may incorporate social desirability effect test, such as self-monitoring (Snyder, 1974: revised by Lennox \& Wolfe, 1984) and the MarloweCrowne Social Desirability Scale (Crowne \& Marlowe, 1960). Respondents' scores in social desirability scales reflect substantive individual cognitive differences and psychometric understanding on the measures.

The second limitation of the present study is the sampling frame. Chosen samples incorporated in the present study were purposively approached and randomly picked through email. Thus, the response-bias problem might affect the result of the present study. Eliminating response-bias is important to ensure the trustfulness of the survey result. Besides, future research can also incorporate a control experimental group (involves the participants within the same ethnic group) to look at the social desirability impact against the measure instrument, especially with regard to the intercultural interactions (Hammer, Bennett \& Wiseman, 2003). Hence, further analysis is granted to check model fit analysis on the structural model as in the present study. Besides, similar investigated is granted to conduct using different set of sojourners (expatriates, immigrant, asylum seekers and tourists) in different country. Lastly, other methods of data collection especially a qualitative study such as interview, observation and participation may provide a significant impact to the intercultural investigation and support the findings of the present study. Utilization of different methods in data collections is granted to measure a consistency of the measure instruments (Portalla \& Chen, 2010).

Particularly, this study helps to provide some insight into sojourners perception on intercultural relations while sojourning abroad. It was revealed that it is an essential for sojourners to develop some portion of intercultural sensitivity when they encounter intercultural differences. Cultural misconception is foreseen through the need to develop more 
structured on-location intercultural training program for sojourners and their families to overcome the cultural challenges (Caligiuri, 2000; Forster, 1997). The present study found that the inconsistencies effect of cultural understanding was due to the different cultural mindset between sojourners and host nationals. Therefore, it is important for both parties to be aware towards the individual cultural differences. Appropriate social learning is essential to eliminate any sign of ethnocentrism, stereotyping or racism. In addition, as contended by Bandura (1977) and Chen (2006), positive attitude and communication competence reduce cultural difficulties in order to ensure the effectiveness of the international assignment. In conclusion, it is important for sojourners to incorporate cultural perspectives in their knowledge and crosscultural adaptation strategies to accommodate effective adjustment abroad.

\section{References}

Adler, P. S. (1975). The Transitional Experience: An Alternative View of Culture Shock. Journal of Humanistic Psychology, 15(4), 13.

Bandura, A. (1977). Self-efficacy: Toward a unifying theory of behavioral change. Psychological Review, 84(2), 191-215.

Berwick, D., Murphy, J., Goldman, P., Ware Jr, J., Barsky, A., \& Weinstein, M. (1991). Performance of a five-item mental health screening test. Medical Care, 29(2), 169-176.

Bjerregaard, T., Lauring, J., \& Klitmoller, A. (2009). A critical analysis of intercultural communication research in cross-cultural management: Introducing newer developments in anthropology. Critical Perspectives on International Business, 5(3), 207-228.

Bhaskar-Shrinivas, P., Harrison, D. A., Shaffer, M. A., \& Luk, D. M. (2005). Input-based and Time-based Models of International Adjustment: Meta-analytic Evidence and Theoritical Extensions. Academy of Management Journal, 48(2), 257-281.

Bhawuk, D. P. S., \& Brislin, R. (1992). The measurement of intercultural sensitivity using the concepts of individualism and collectivism. International Journal of Intercultural Relations, 16(4), 413-436.

Brein, M., \& David, K. H. (1971). Intercultural communication and the adjustment of the Sojourner. Psychological Bulletin, 76(3), 215230.

Buckley, P. J., Clegg, J., \& Tan, H. (2006). Cultural awareness in knowledge transfer to China--The role of guanxi and mianzi. Journal of World Business, 41(3), 275-288.

Caligiuri, P. M. (2000). The Big Five personality characteristics as predictors of expatriate's desire to terminate the assignment and supervisor-rated performance. Personnel Psychology, 53(1), 67-88.

Chen, G.-M. (2006). Asian Communication Studies: What and Where to Now. Review of Communication, 6(4), 295 - 311.

Chen, G., \& Starosta, W. (1996). Intercultural communication competence: A synthesis. Communication yearbook, 19, 353-384.

Chen, G., \& Starosta, W. (2000). The Development and Validation of the Intercultural Sensitivity Scale. Paper presented at the Annual Meeting of the National Communication Association, Seattle, WA.

Clausen, L. (2010). Moving beyond stereotypes in managing cultural difference: Communication in Danish-Japanese corporate relationships. Scandinavian Journal of Management, 26(1), 57-66. Colombijn, F. (2002). Explaining the Violent Solution in Indonesia. The Brown Journal of World Affairs, 9(1), 49-56.

Colombijn, F. (2002). Explaining the Violent Solution in Indonesia. The Brown Journal of World Affairs, 9(1), 49-56.

Crowne, K., Phatak, A., \& Salunkhe, U. (2009). Does culture influence intelligence? A study of the influence of cultural context. Emotions in Groups, Organizations and Cultures, 275.

Dong, Q., Day, K., \& Collaco, C. (2008). Overcoming ethnocentrism through developing intercultural communication sensitivity and multiculturalism. Human Communication, 11(1), 27-38.

Forster, N. (1997). 'The persistent myth of high expatriate failure rates': a reappraisal. International Journal of Human Resource Management, 8(4), 414-433.

Friedman, P. A., Dyke, L. S., \& Murphy, S. A. (2009). Expatriate adjustment from the inside out: An autoethnographic account. International Journal of Human Resource Management, 20(2), 252-268.

Fritz, W., Mollenberg, A., \& Chen, G. (2002). Measuring intercultural sensitivity in different cultural context. Intercultural Communication Studies, 11(2), 165-176.

Global Relocation Trends Survey (GRTS) (2009), 2009 Survey Reports, Brookfield Global Relocation Services and National Foreign Trade Council (NFTC) http://www.brookfieldgrs.com/insights_ideas/grts/index.asp [retrieved on 23rd January 2010

Global Relocation Trends Survey (GRTS) (2010), 2010 Survey Reports, Brookfield Global Relocation Services and National Foreign Trade Council (NFTC) http://www.brookfieldgrs.com/insights_ideas/grts/index.asp [retrieved on 13 th January 2011]

Graf, A. (2004). Assessing intercultural training designs. Journal of European Industrial Training, 28(2), 199-214.

Greenholtz, J. F. (2005). Does intercultural sensitivity cross cultures? Validity issues in porting instruments across languages and cultures. International Journal of Intercultural Relations, 29(1), 73-89.

Gudykunst, W. B., \& Nishida, T. (2001). Anxiety, uncertainty, and perceived effectiveness of communication across relationships and cultures. International Journal of Intercultural Relations, 25(1), 55-71.

Hall, E. T. (1959). The Silent Language. New York: Anchor Press.

Hair, J., Black, W., Babin, B., Anderson, R., \& Tatham, R. (2006). Multivariate Data Analysis (2006): Upper Saddle River, NJ: Prentice Hall.

Hammer, M., Bennett, M., \& Wiseman, R. (2003). Measuring intercultural sensitivity: The intercultural development inventory. International Journal of Intercultural Relations, 27(4), 421-443. 
Henseler, J., Ringle, C. M., \& Sinkovics, R. R. (2009). The use of partial least squares path modeling in international marketing. Advances in international marketing, 20(2009), 277-319.

Hofstede, G. (1983). The cultural relativity of organizational practices and theories. Journal of International Business Studies, 14(2), 7589.

Lennox, R. D., \& Wolfe, R. N. (1984). Revision of the Self-Monitoring Scale. Journal of Personality and Social Psychology, 46(6), 13491364.

Lewthwaite, M. (1996). A study of international students' perspectives on cross-cultural adaptation. International Journal for the Advancement of Counselling, 19(2), 167-185.

Matveev, A. V., \& Milter, R. G. (2004). The value of intercultural competence for performance of multicultural teams. Team Performance Management, 10(5/6), 104-111.

Mendenhall, M., Stevens, M., Bird, A., \& Oddou, G. (2008). Specification of the content domain of the Intercultural Effectiveness Scale. The Kozai Monograph Series, 1(2).

Oberg, K. (1960). Culture shock: Adjustments to new cultural environments. Practical Anthropology, 4, 177-182.

Ones, D. S., \& Viswesvaran, C. (1999). Relative importance of personality dimensions for expatriate selection: A policy capturing study. Human Performance, 12(3-4), 275-294.Portalla, T., \& Chen, G.-M. (2010). The Development and Validation of the Intercultural Effectiveness Scale. Intercultural Communication Studies, 19(3).

Peng, S.-Y. (2006). A Comparative Perspective of Intercultural Sensitivity Between College Students and Multinational Employees in China. Multicultural Perspectives, 8(3), 38 - 45.

Portalla, T., \& Chen, G.-M. (2010). The Development and Validation of the Intercultural Effectiveness Scale. Intercultural Communication Studies, 19(3).

Rasmussen, T., Lloyd, C., \& Wielandt, T. (2005). Cultural awareness among Queensland undergraduate occupational therapy students. Australian Occupational Therapy Journal, 52(4), 302-310.

Searle, W., \& Ward, C. (1990). The prediction of psychological and sociocultural adjustment during cross-cultural transitions. International Journal of Intercultural Relations, 14(4), 449-464.

Selmer, J. (2004). Psychological barriers to adjustment of Western business expatriates in China: newcomers vs long stayers. International Journal of Human Resource Management, 15(4/5), 794-813.

Shaftel, J., Shaftel, T., \& Ahluwalia, R. (2007). International Educational Experience and Intercultural Competence. International Journal of Business and Economics, 6(1), 25-34.

Snyder, M. (1974). Self-monitoring of expressive behavior. Journal of Personality and Social Psychology, 30(4), 526.

Stahl, G. K. (2000). Between Ethnocenterism \& Assimilation: An Exploratory Study of the Challenges \& Coping Strategies of Expatriate Managers. Paper presented at the Academy of Management Proceedings \& Membership Directory.

Torbiorn, I. (1985). The Structure of Managerial roles in Cross-cultural Settings. International Studies of Management \& Organization, $15(1), 52-74$.

UNESCO. (2009). UNESCO World Report: Investing in Cultural Diversity and Intercultural Dialogue: UNESCO Publishing

Ward, C., Bochner, S., \& Furnham, A. (2001). The Pschology of Culture Shock (2nd Edition). East Sussex, England: Routledge.

Ward, C., \& Kennedy, A. (1999). The measurement of sociocultural adaptation. International Journal of Intercultural Relations, 23(4), 659-677.

Williams, T. R. (2005). Exploring the Impact of Study Abroad on Students' Intercultural Communication Skills: Adaptability and Sensitivity. Journal of Studies in International Education, 9(4), 356-371.

Yu, T., \& Chen, G. (2008). Intercultural Sensitivity and Conflict Management Styles in Cross-cultural Organizational Situations. Intercultural Communication Studies, 17(2), 149-161. 